\title{
Synchronous condenser operation in Francis turbines: Effects in the runner stress and machine vibration
}

\section{David Valentín ${ }^{\mathrm{a},}$}

david.valentin@upc.edu

\section{Alexandre Presas}

Carme Valero

Mònica

Eduard Egusquiza

aCenter for Industrial Diagnostics and Fluid Dynamics (CDIF), Universitat Politècnica de Catalunya (UPC), Av. Diagonal, 647, ETSEIB, 08028, Barcelona, Spain

${ }^{*}$ Corresponding author.

\section{Abstract}

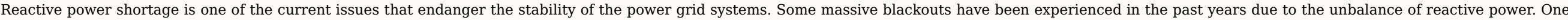

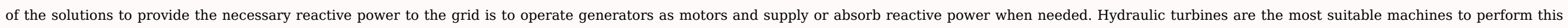
task since they can be easily and quickly dewatered to work as motors (Synchronous Condenser (SC) operation).

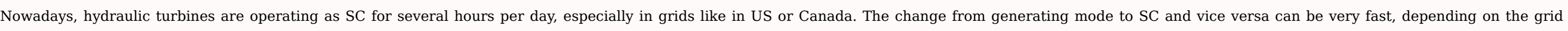

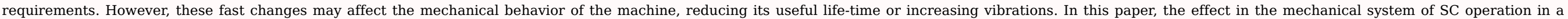
Francis turbine prototype is evaluated. Strains in the runner and vibrations in the stationary parts are analyzed in detail in the fast changes between generating to SC and vice versa.

Keywords: Hydropower; Synchronous condenser; Francis turbine; Reactive power; Grid stability

\section{Introduction}

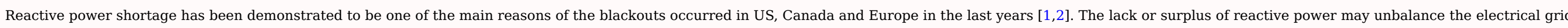

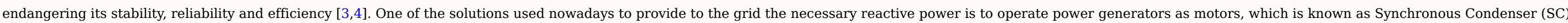

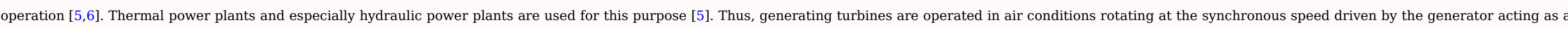

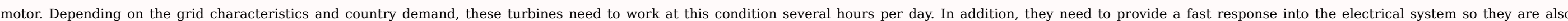
subjected to fast transients to go from generating to SC mode or vice versa.

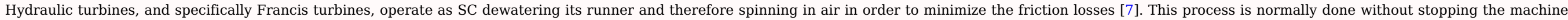

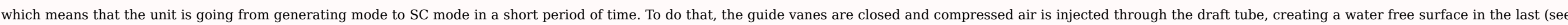

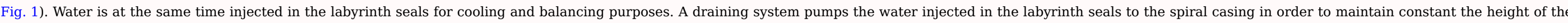
free surface. Therefore, the runner in this situation is rotating in air and consuming active power from the electrical grid. 


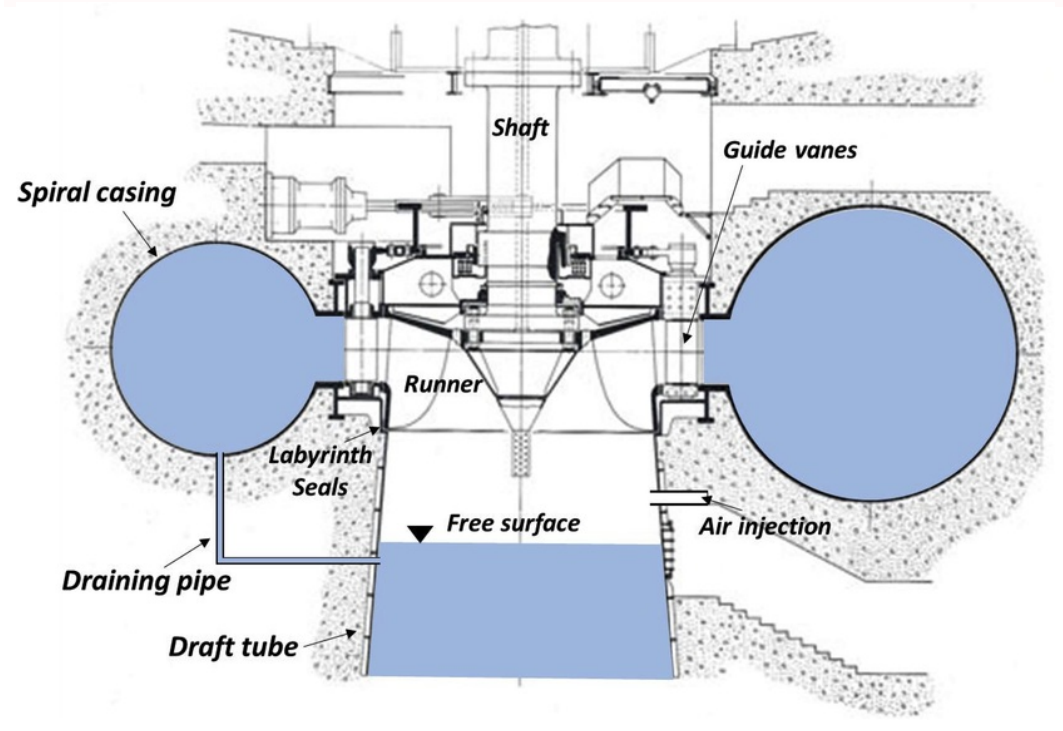

Fig. 1 Francis turbine dewatered for SC operation.

\section{alt-text: Fig. 1}

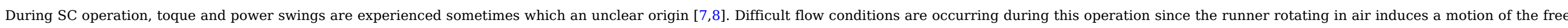

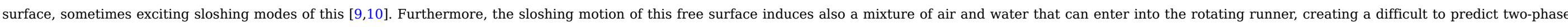

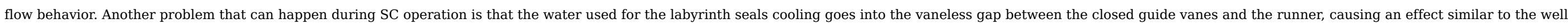

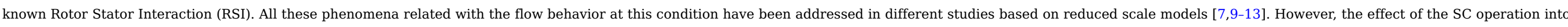

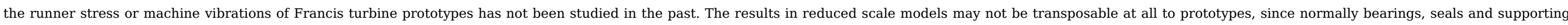

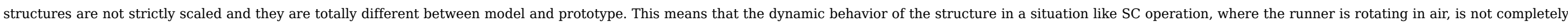
transposable, hence analyzing the dynamic behavior in the prototype is essential.

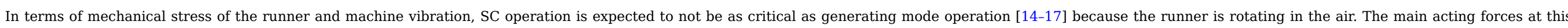

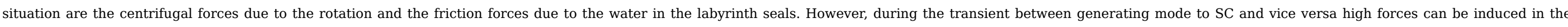

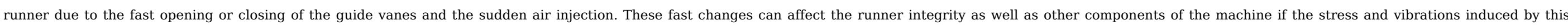
condition are high enough. In addition, if SC operation is increasingly required, fatigue problems can appear in the turbine components.

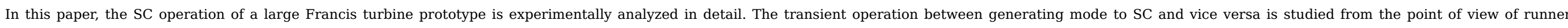

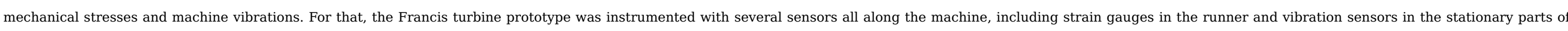

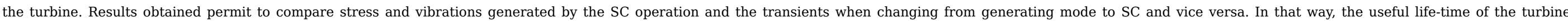
components can be compared and evaluated.

\section{Experimental investigation}

\subsection{Prototype characteristics}

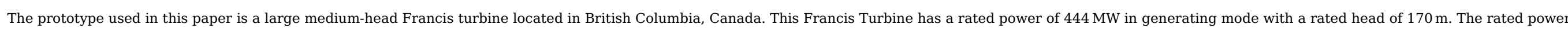

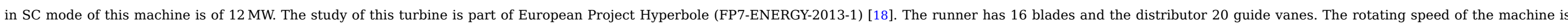




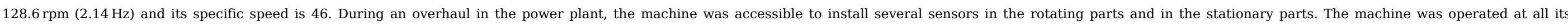
operating range, including SC operation, in order to determine its dynamic behavior.

\subsection{Instrumentation}

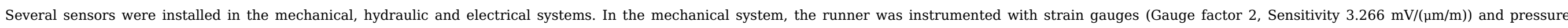

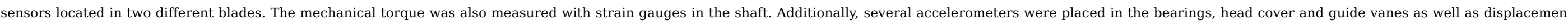

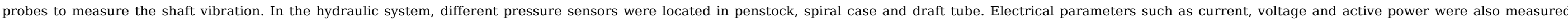
simultaneously. The operating conditions signals of guide vane opening and rotating speed were also measured.

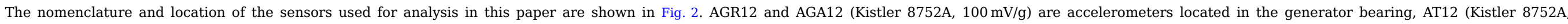

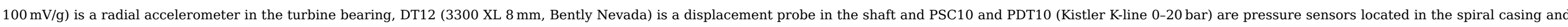

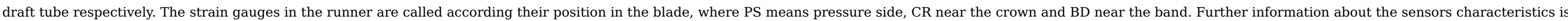
found in Refs. [14-16,19-21].
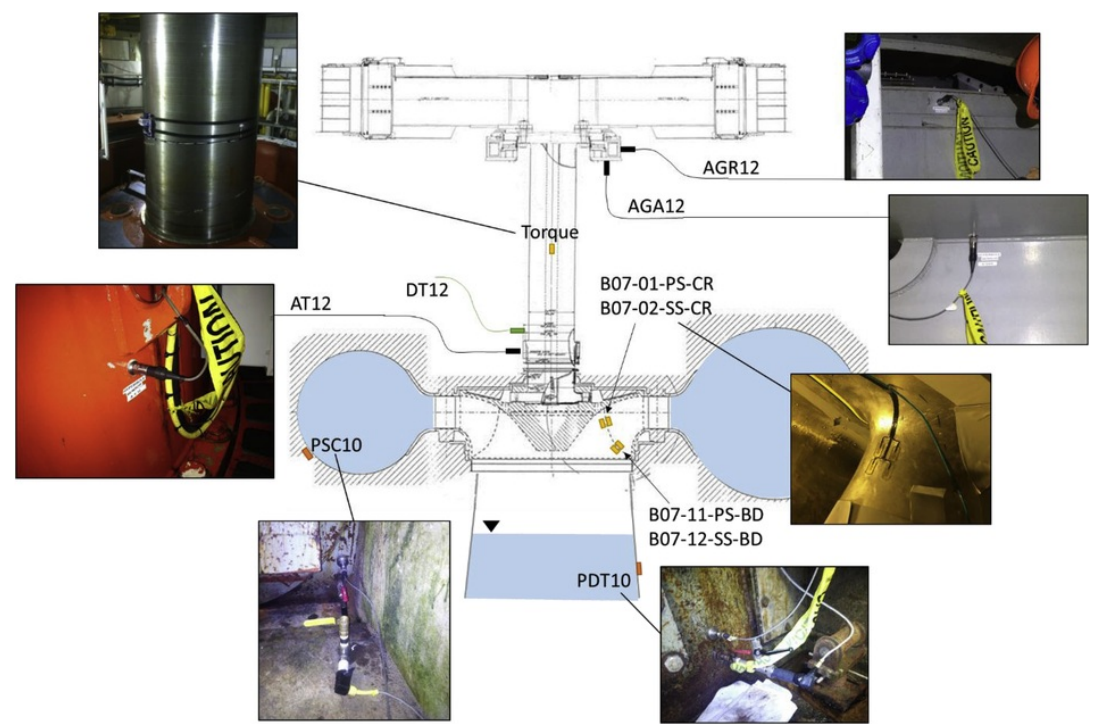

PDT10

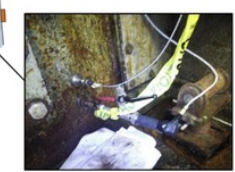

Fig. 2 Position and picture of the sensors used for the analysis.

\section{alt-text: Fig. 2}

\subsection{Acquisition}

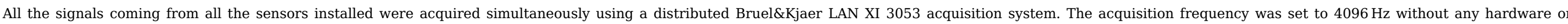
software filtering.

\subsection{Testing procedure}

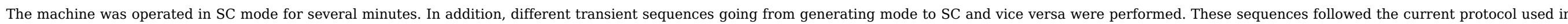

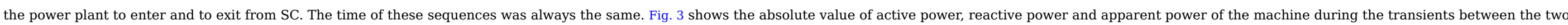

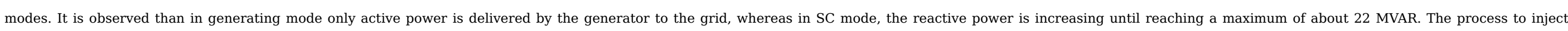



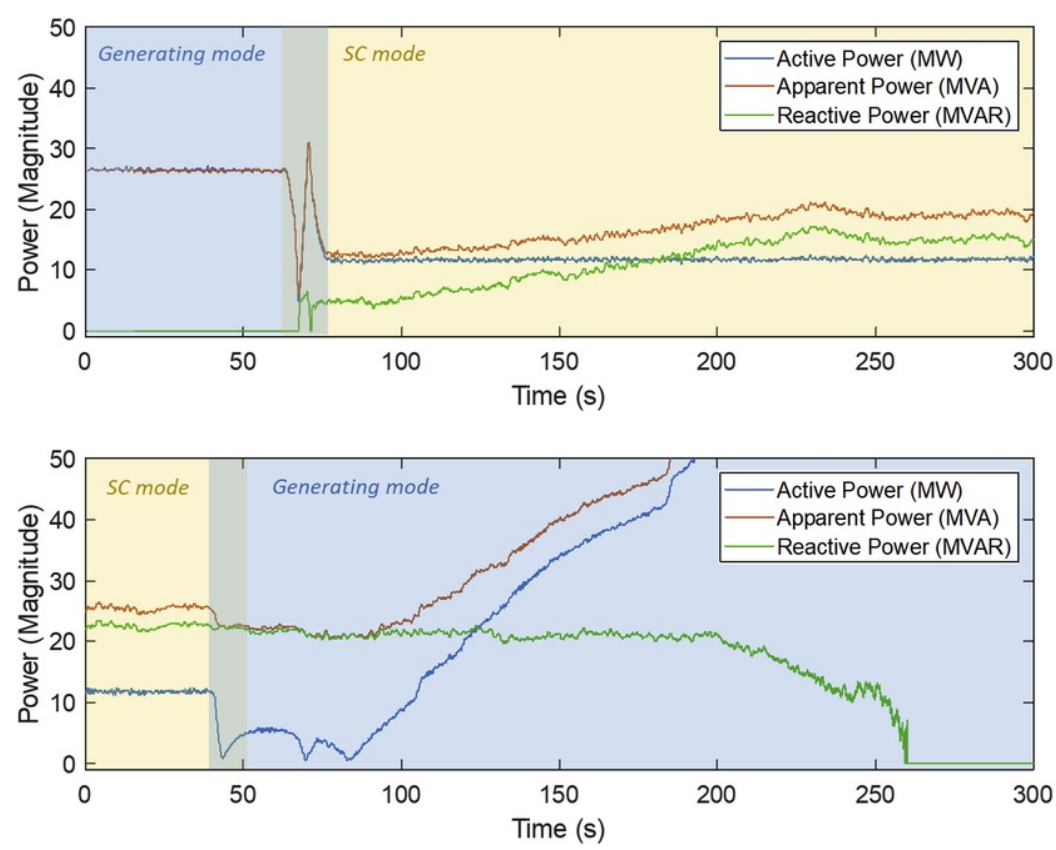

Fig. 3 Absolute values of Active Power, Reactive Power and Apparent Power during the transitions from generating mode to SC (up) and vice versa (down). alt-text: Fig. 3

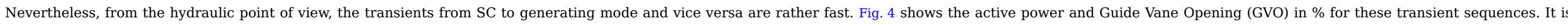

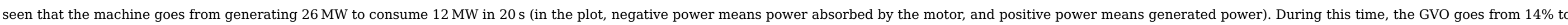

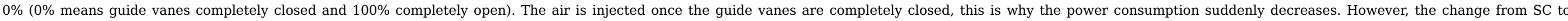

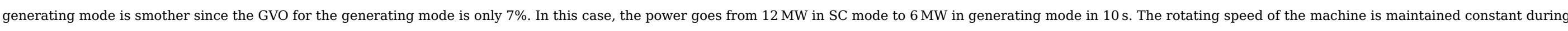
the transient sequences.
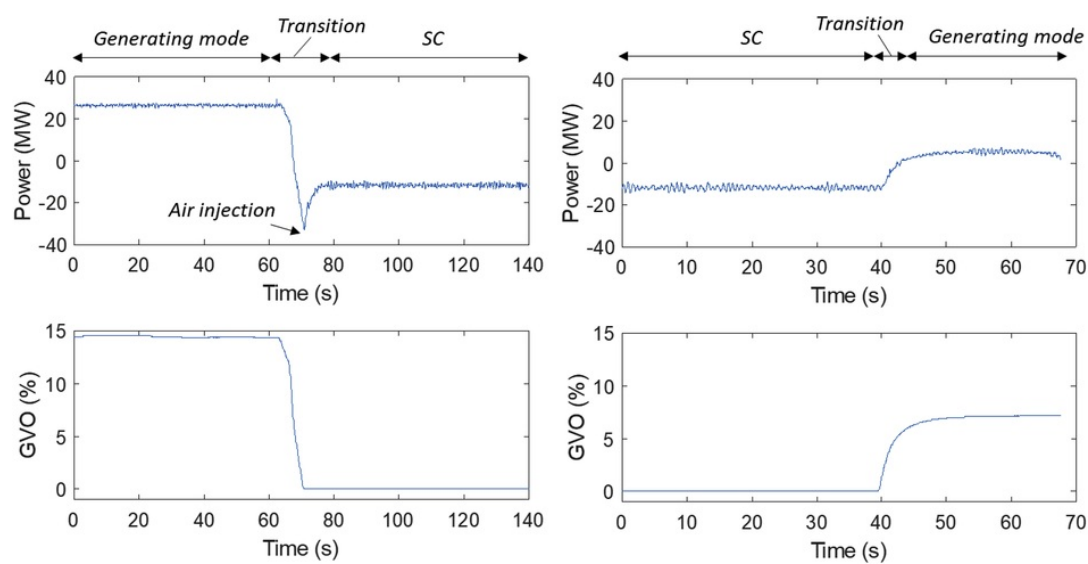


\subsection{Signal analysis}

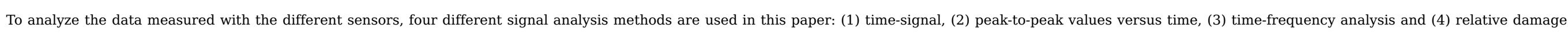
estimation due to fatigue.

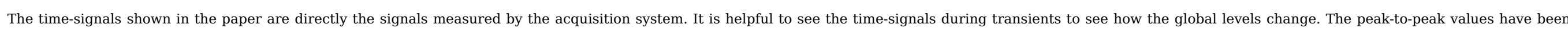

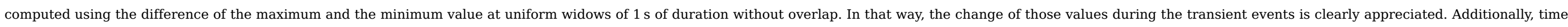

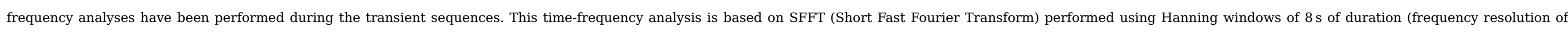
$0.25 \mathrm{~Hz}$ ) with an overlap of $95 \%$ between them.

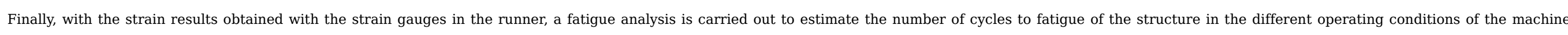

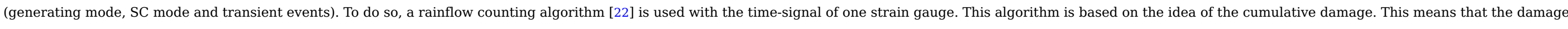
caused by the different excitations due to different frequencies and amplitudes can be summed to obtain the total damage.

\section{Results and discussion}

\subsection{Time-signals}

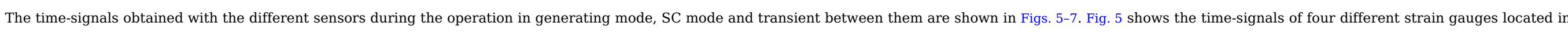

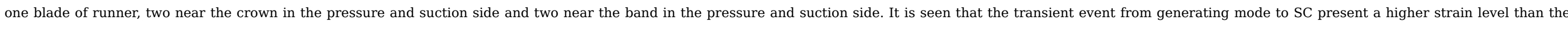

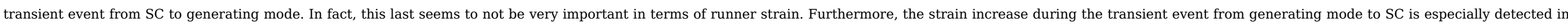

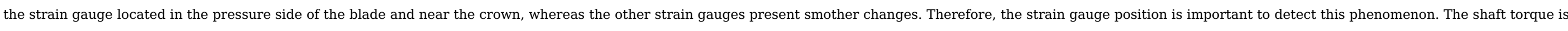
also seen in Fig. 5. In this case, the torque behavior is the same than the electrical power presented in Fig. 4.
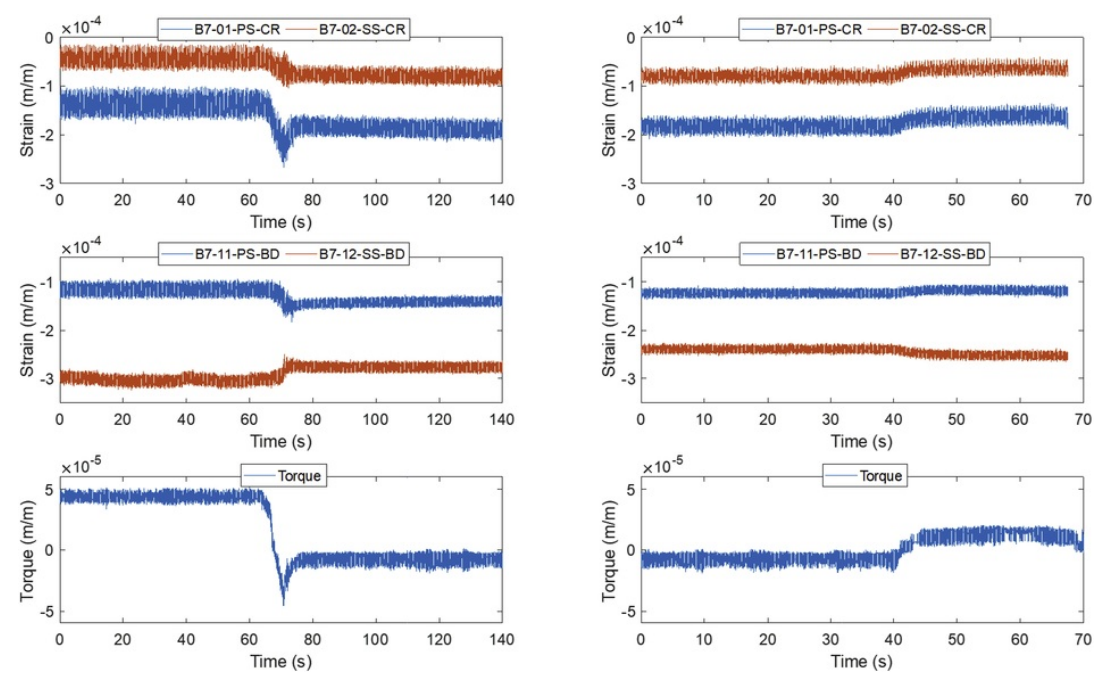

Fig. 5 Time-signals of the runner strain gauges and torque shaft during the transient sequences. From generating mode to SC (left) and vice versa (right). alt-text: Fig. 5 

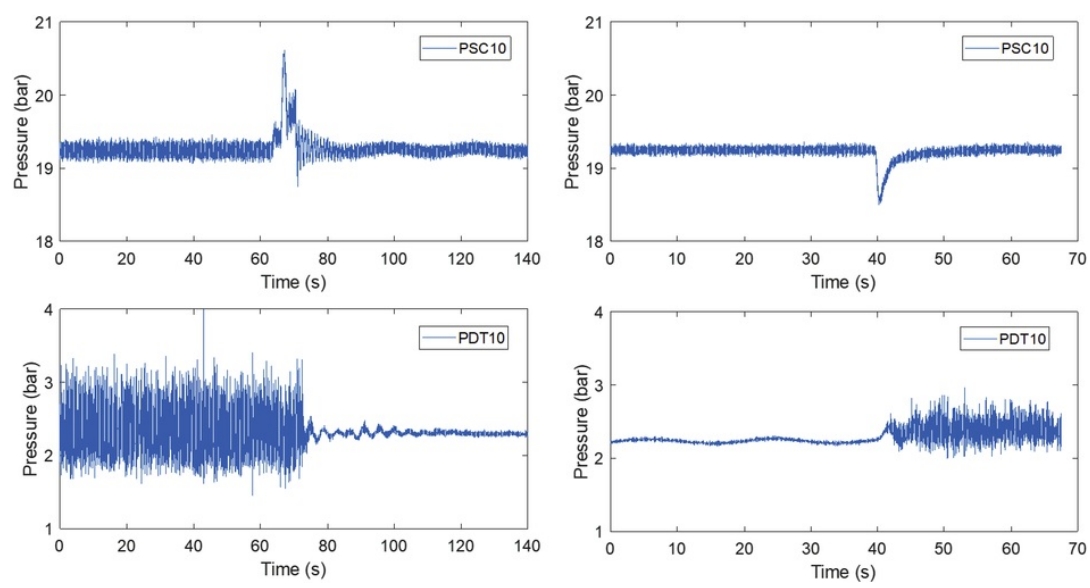

Fig. 6 Time-signals of the pressure sensors in the spiral casing (PSC10) and in the draft tube (PDT10) during the transient sequences. From generating mode to SC (left) and vice versa (right). alt-text: Fig. 6
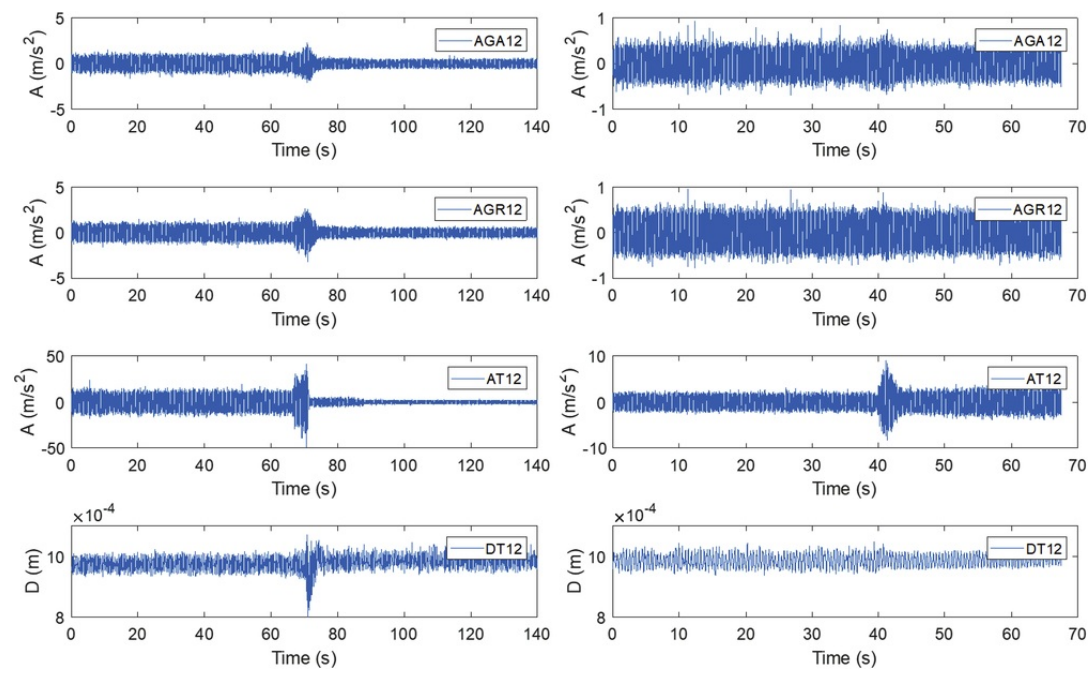

Fig. 7 Time-signals of the accelerometers in the bearings and the displacement probe in the turbine bearing during the transient sequences. From generating mode to SC (left) and vice versa (right). alt-text: Fig. 7

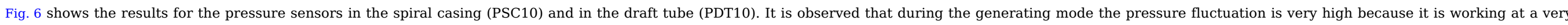

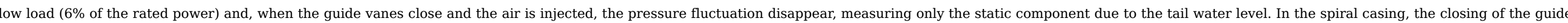
vanes produces an instantaneous overpressure that reaches about 2 bar amplitude.

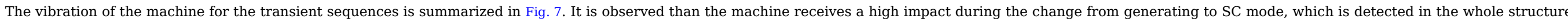

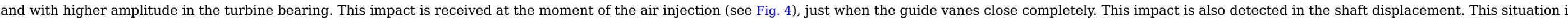

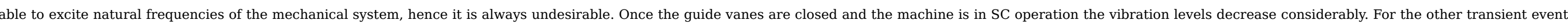
from SC to generating mode, the vibration levels are not that high, being only detectable an impact with less energy than before in the turbine bearing. 


\subsection{Peak-to-peak values}

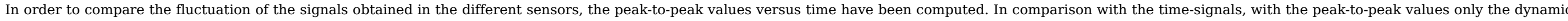

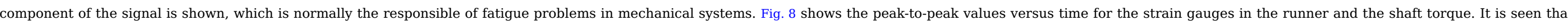

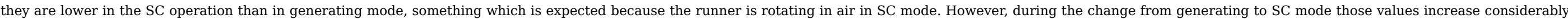

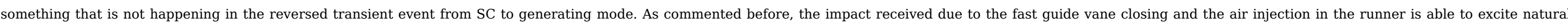
frequencies of the whole system, increasing therefore the dynamic component of the signals.
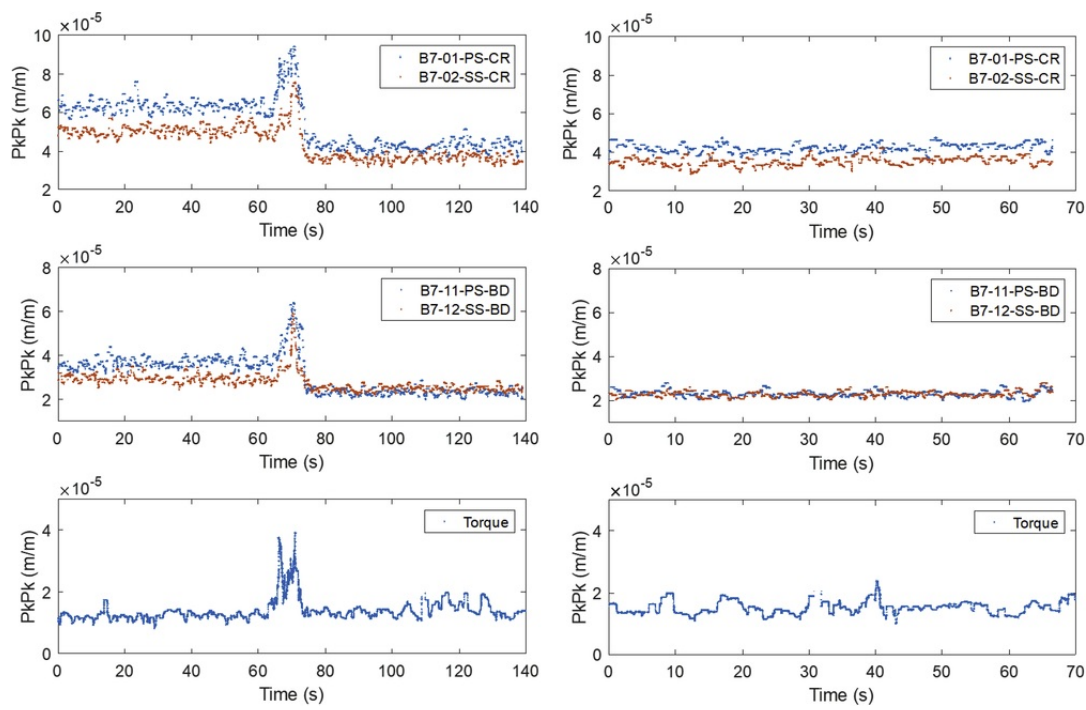

Fig. 8 Peak-to-peak values of the runner strains and torque shaft during the transient sequences. From generating mode to SC (left) and vice versa (right). alt-text: Fig. 8

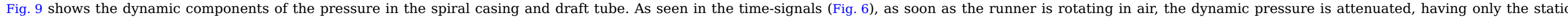
pressure of the upper and lower reservoir in the spiral casing and draft tube respectively.
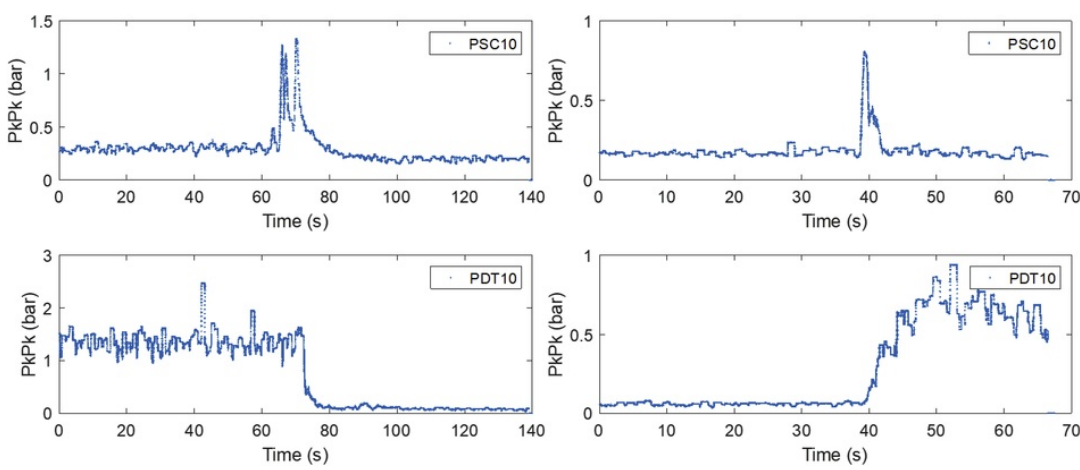

Fig. 9 Peak-to-peak values of the pressure sensors in the spiral casing (PSC10) and in the draft tube (PDT10) during the transient sequences. From generating mode to SC (left) and vice versa (right). alt-text: Fig. 9 


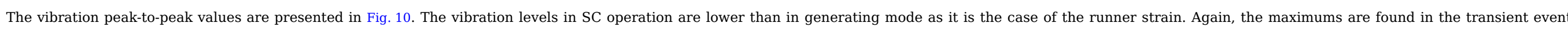

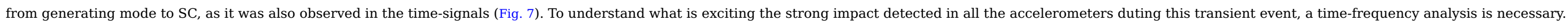
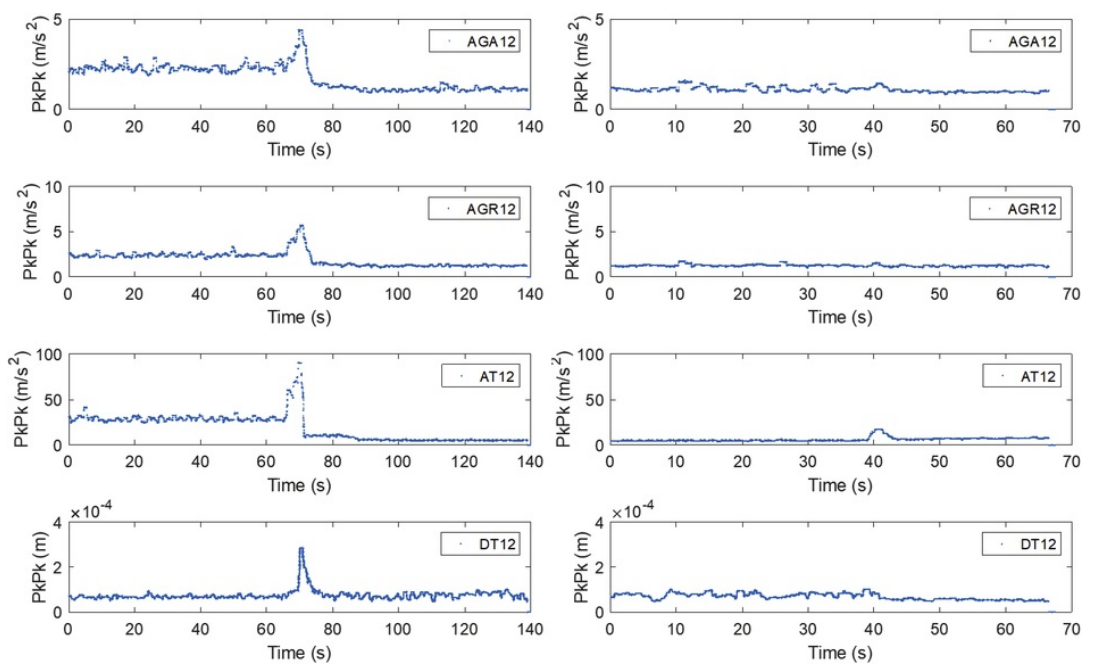

Fig. 10 Peak-to-peak values of the accelerometers in the bearings and the displacement probe in the turbine bearing during the transient sequences. From generating mode to SC (left) and vice versa (right). alt-text: Fig. 10

\subsection{Time-frequency}

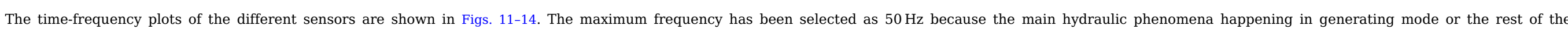

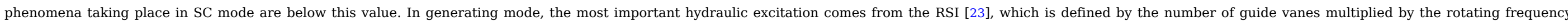

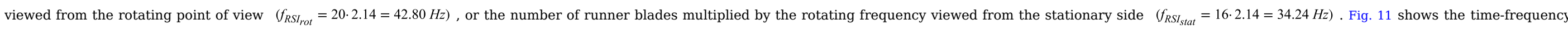

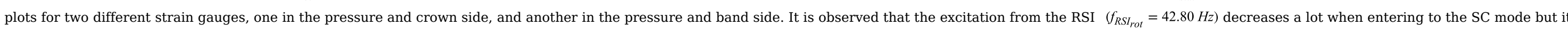

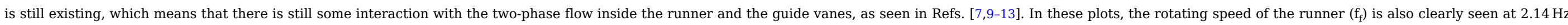

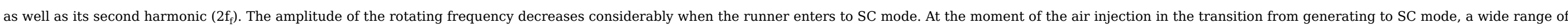
frequencies is excited in the runner. However, in the transition event from SC to generating mode, these frequencies are not excited since the transition is smother. 

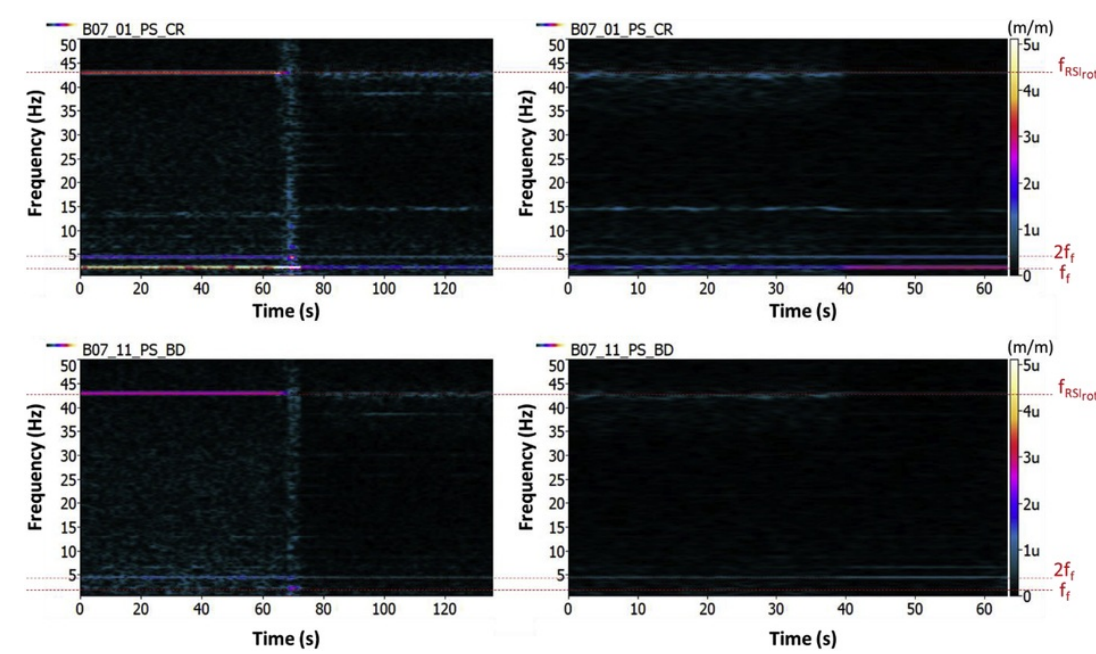

Fig. 11 Time-frequency plot of the runner strains and torque shaft during the transient sequences. From generating mode to SC (left) and vice versa (right). alt-text: Fig. 11
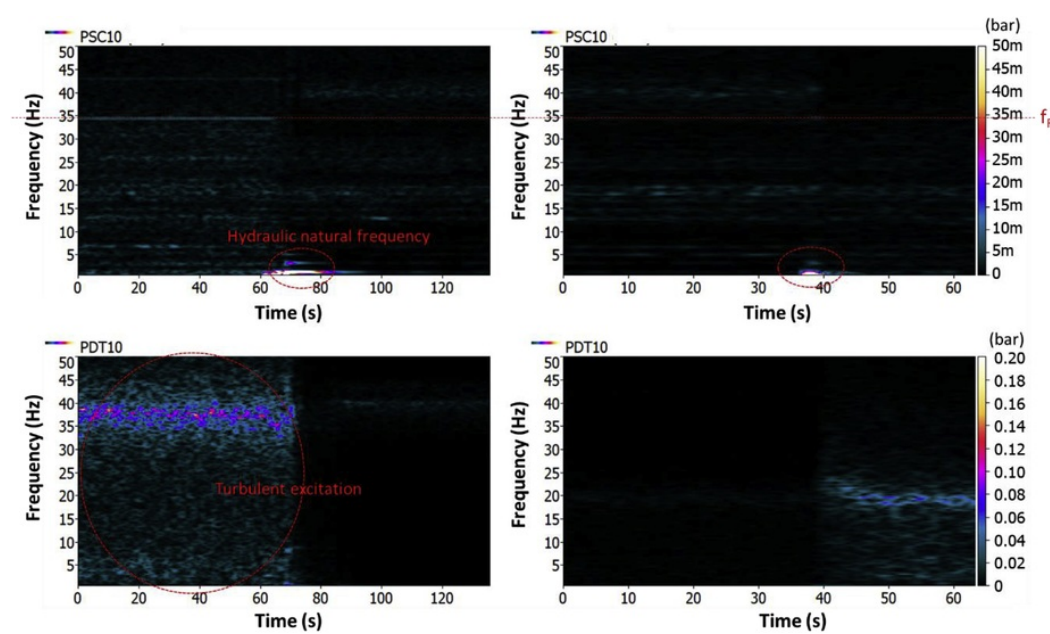

Fig. 12 Time-frequency plot of the pressure sensors in the spiral casing (PSC10) and in the draft tube (PDT10) during the transient sequences. From generating mode to SC (left) and vice versa (right). alt-text: Fig. 12 

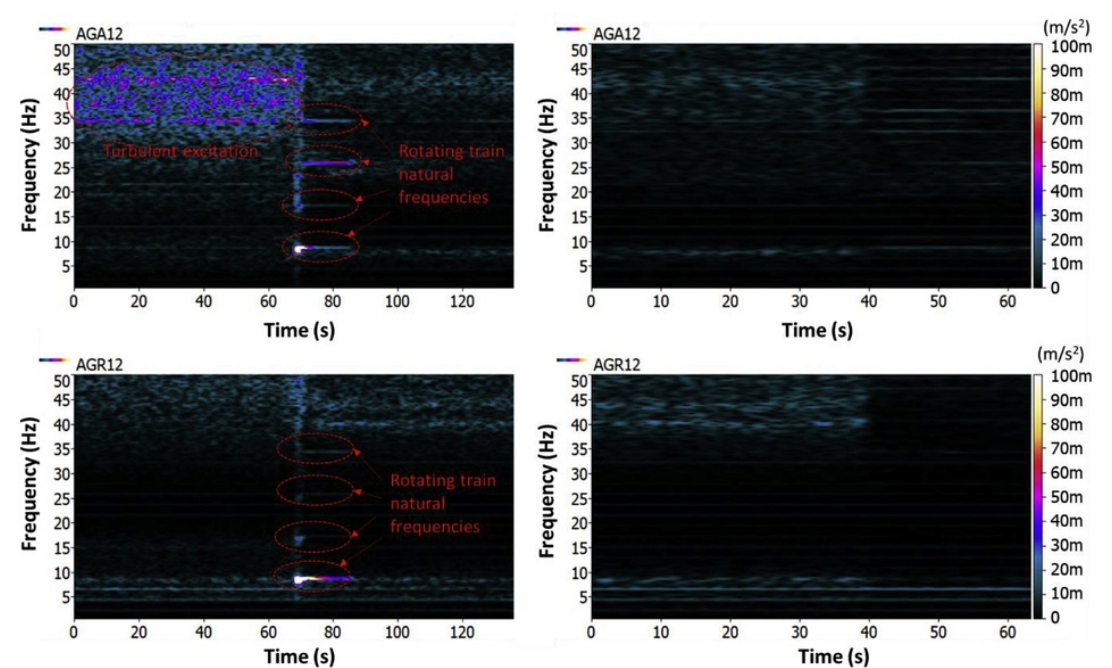

Fig. 13 Time-frequency plot of the accelerometers in the generator bearing during the transient sequences. From generating mode to SC (left) and vice versa (right). alt-text: Fig. 13
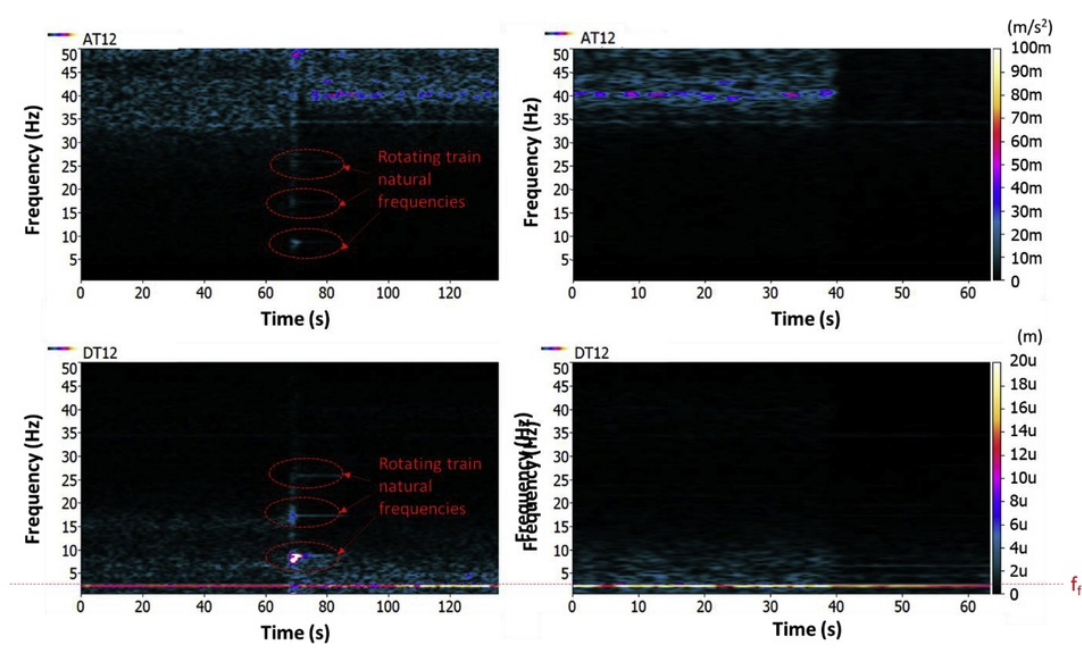

Fig. 14 Time-frequency plot of the accelerometer (AT12) and the displacement probe (DT12) in the turbine bearing during the transient sequences. From generating mode to SC (left) and vice versa (right). alt-text: Fig. 14

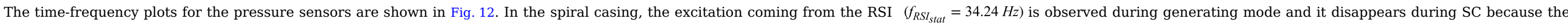

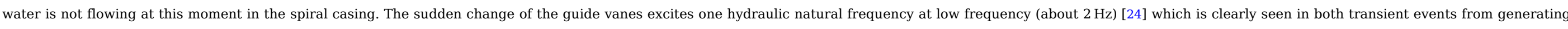

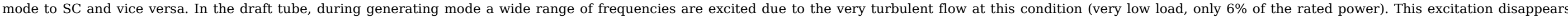
completely once in SC mode.

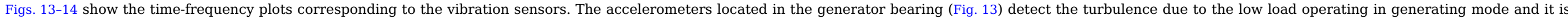

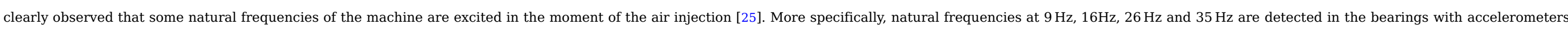




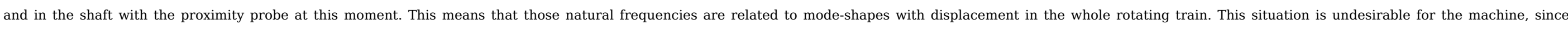
vibration increases considerably. In the transient event from SC to generating mode, which is smother, those natural frequencies are not excited.

\subsection{Fatigue estimation}

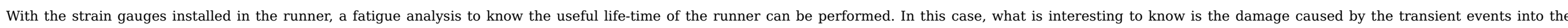

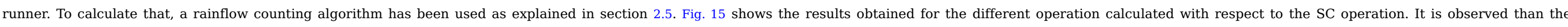

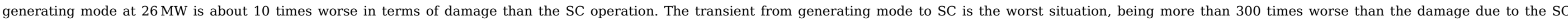

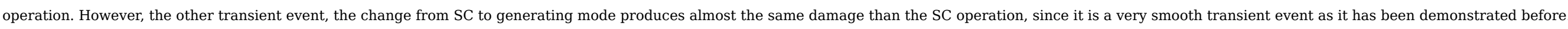

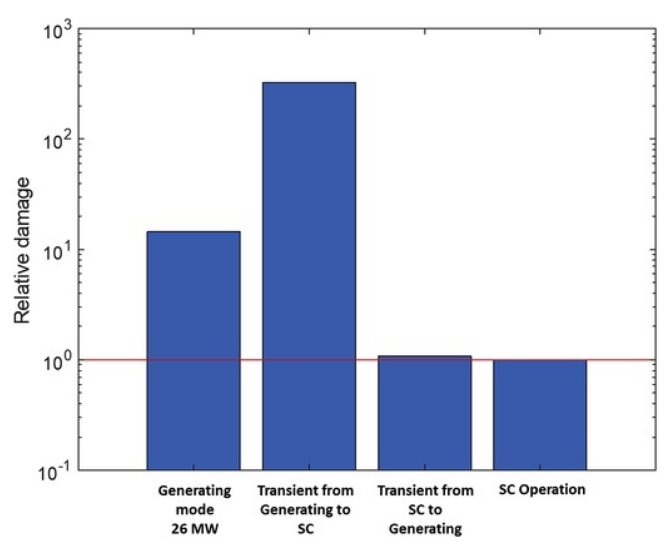

Fig. 15 Relative damage calculated with the strain gauges in the runner for the different operations. Values normalized against the SC operation alt-text: Fig. 15

\section{Conclusions}

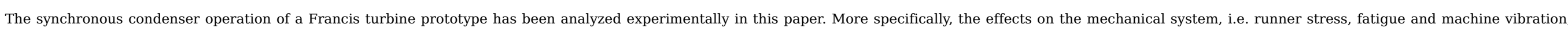

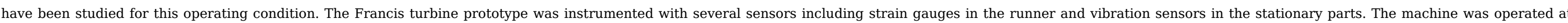
synchronous condenser mode for several minutes. Furthermore, the actual sequences used in the power plant to go from generating mode to synchronous condenser and vice versa have been also studied.

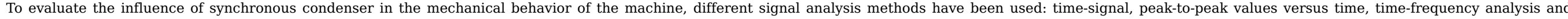

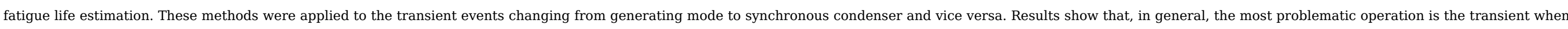
changing from generating mode to synchronous condenser.

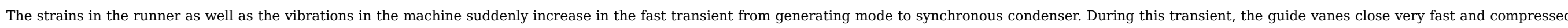

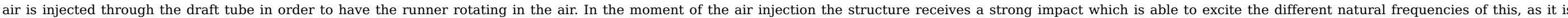
demonstrated with the time-frequency plots. The vibration and strain levels increase substantially at this moment, making this transient event a critical situation to take into account.

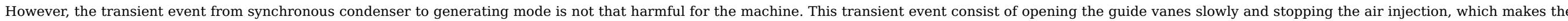

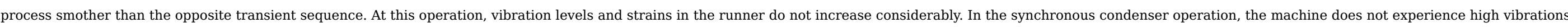
or strains in comparison with the generating mode operation. This behavior is expected because the runner is rotating in the air.

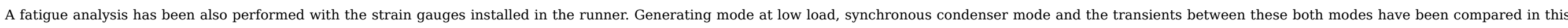

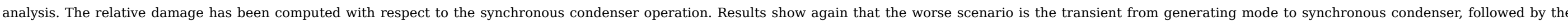




\section{Acknowledgements}

The authors would like to acknowledge HYPERBOLE research project, granted by the European Commission (ERC/FP7-ENERGY-2013-1-Grant 608532).

The authors would also like to thank BC Hydro for making possible the experimental tests in the prototype and Voith and GE teams for the strain gauges and pressure sensors installation.

\section{Appendix A. Supplementary data}

Supplementary data to this article can be found online at https://doi.org/10.1016/j.renene.2019.07.041.

\section{References}

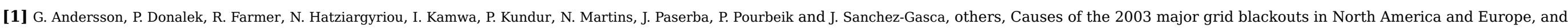
recommended means to improve system dynamic performance, IEEE Trans. Power Syst. 20, 2005, 1922-1928.

[2] Y.V. Makarov, V.I. Reshetov, A. Stroev and I. Voropai, Blackout prevention in the United States, Europe, and Russia, Proc. IEEE 93, 2005, 1942-1955.

[3] J. Dixon, L. Moran, J. Rodriguez and R. Domke, Reactive power compensation technologies: state-of-the-art review, Proc. IEEE 93, $2005,2144-2164$.

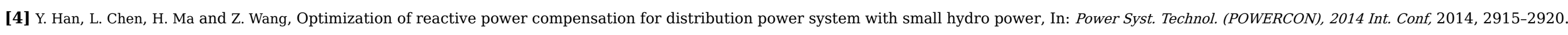

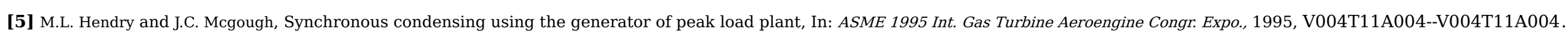

[6] S.S. Kalsi, D. Madura and M. Ingram, Superconductor synchronous condenser for reactive power support in an electric grid, IEEE Trans. Appl. Supercond. 15, 2005 , $2146-2149$.

[7] E. Vagnoni, Two-phase Flow Phenomena in Hydraulic Turbines and Pump-Turbines Operating in Synchronous Condenser Mode, 2018, EPFL.

[8] T. Tanaka, Sloshing motion of the depressed water in the draft tube in dewatered operation of high head pump-turbines, In: Proc. 17th IAHR Sympo, 1, $1994,121$.

[9] E. Vagnoni, L. Andolfatto and F. Avellan, On the sloshing free surface in the draft tube cone of a Francis turbine operating in synchronous condenser mode, In: J. Phys. Conf. Ser, 2017 , 12034.

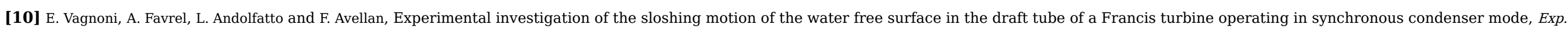
Fluid 59, 2018, 95.

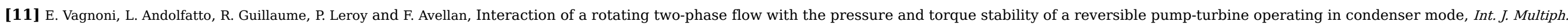
Flow 111, 2019, 112-121.

[12] H. Tanaka, Vibration behavior and dynamic stress of runners of very high head reversible pump-turbines, Int. J. Fluid Mach. Syst. 4, 2011, 289-306.

[13] G. Rossi and V. Zanetti, Starting in air and synchronous condenser operation of pump-turbines-model research, In: 9th IAHR-SHMEC Symp, 1978, 337-352.

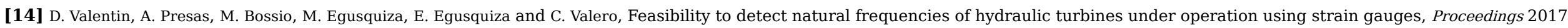
https://doi.org/10.3390/proceedings1080821.

[15] D. Valentín, A. Presas, E. Egusquiza, C. Valero, M. Egusquiza and M. Bossio, Power swing generated in Francis turbines by Part Load and overload instabilities, Energies 10, 2017, 2124.

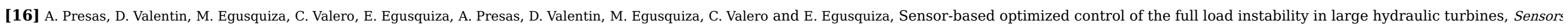
18, 2018, 1038, https://doi.org/10.3390/s18041038.

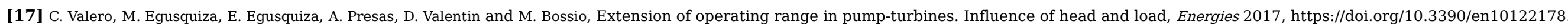


[18] Hyperbole Project, HYdropower plants PERformance and flexiBle Operation towards Lean integration of new renewable Energies, https://hyperbole.epfl.ch, 2013.

[19] J.G. Pereira, Jr., L. Andolfatto and F. Avellan, Monitoring a Francis turbine operating conditions, Flow Meas. Instrum. 63, 2018, 37-46.

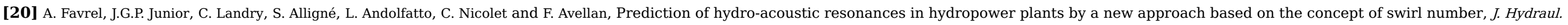
Res. 0, 2019, 1-18, https://doi.org/10.1080/00221686.2018.1555556.

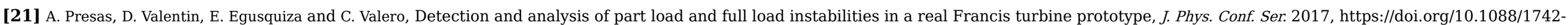
$6596 / 813 / 1 / 012038$.

[22] S.D. Downing and D.F. Socie, Simple rainflow counting algorithms, Int. J. Fatigue 4, 1982, 31-40 https://doi.org/10.1016/0142-1123(82)90018-4.

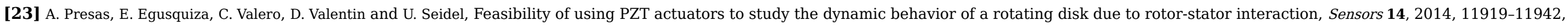
https://doi.org/10.3390/s140711919.

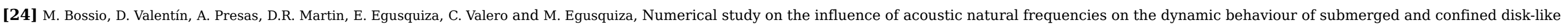
structures, J. Fluids Struct. 73, 2017, 53-69 https://doi.org/10.1016/j.jfluidstructs.2017.05.008.

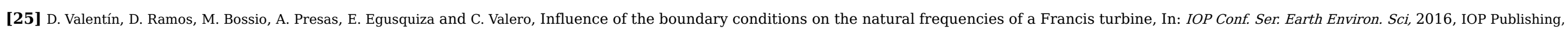
72004 .

\section{Appendix A. Supplementary data}

The following is the Supplementary data to this article:

Multimedia Component 1

Multimedia component 1

alt-text: Multimedia component 1

\section{Highlights}

- Synchronous condenser operation in a Francis turbine has been studied.

- Runner stress and fatigue have been evaluated for this operating condition.

- Vibration behavior of the machine is studied during synchronous condenser operation.

- Transient events from generating mode to synchronous condenser and vice versa are investigated.

\section{Queries and Answers}

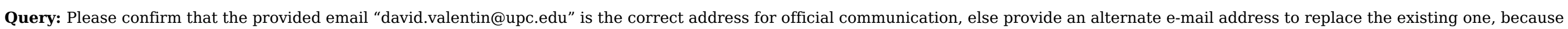
private e-mail addresses should not be used in articles as the address for communication.

Answer: Yes, it is the correct address

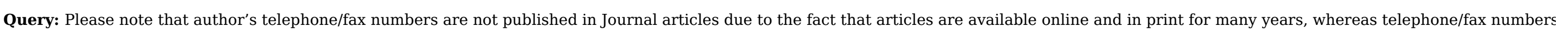


are changeable and therefore not reliable in the long term.

\section{Answer: Ok}

Query: Have we correctly interpreted the following funding source(s) and country names you cited in your article: European Commission, European Union?

Answer: Yes

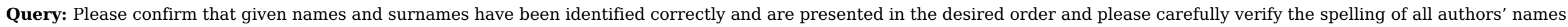

Answer: Yes

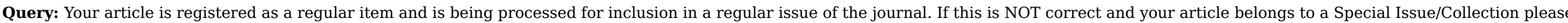
contact v.subramanian@elsevier.com immediately prior to returning your corrections.

Answer: Yes 